\title{
Biotic/Abiotic Stress-Driven Alzheimer's Disease
}

\author{
Chang-Qing $\mathrm{Li}^{1}$, Qing Zheng ${ }^{2}$, Qi Wang ${ }^{3 *}$ and Qing-Ping Zeng ${ }^{1 *}$ \\ ${ }^{1}$ Tropical Medicine Institute, Guangzhou University of Chinese Medicine, Guangzhou, China, ${ }^{2}$ Department of \\ Biopharmaceutics, College of Pharmacy, Jinan University, Guangzhou, China, ${ }^{3}$ Clinical Pharmacology Institute, Guangzhou \\ University of Chinese Medicine, Guangzhou, China
}

Keywords: Alzheimer's disease (AD), biotic stress, abiotic stress, gut microbiota, opportunistic infection, lipopolysaccharide (LPS), reactive oxygen species (ROS), reactive nitrogen species (RNS)

\section{INTRODUCTION}

Alzheimer's disease (AD), a neurodegenerative condition, is characterized by deficient synaptic plasticity, dramatic neuronal dysfunction, and massive neuronal loss. Apart from familial or early-onset $\mathrm{AD}(5-10 \%)$, most $\mathrm{AD}$ cases are non-familial or late-onset/sporadic (90-95\%; Ballard et al., 2011) with a complicated etiology. Some competing theories have been suggested regarding the cause of AD, such as the amyloid hypothesis (Hardy and Allsop, 1991) and tau hypothesis (Mudher and Lovestone, 2002), but minimal data on initial triggers are available despite intensive explorations over recent decades.

We summarized the published evidence into an opinion that deciphers how the multifaceted

OPEN ACCESS

Edited by: Egidio D'Angelo,

University of Pavia, Italy

Reviewed by:

Fabio Blandini,

Fondazione Instituto Neurologico Nazionale Casimiro Mondino (IRCCS),

Italy

Sim K. Singhrao,

University of Central Lancashire, UK

*Correspondence:

Qi Wang

wangqi@gzucm.edu.cn

Qing-Ping Zeng

qpzeng@163.com

Received: 23 May 2016 Accepted: 07 November 2016 Published: 23 November 2016

Citation: Li C-Q, Zheng Q, Wang $Q$ and Zeng Q-P (2016) Biotic/Abiotic Stress-Driven Alzheimer's Disease.

Front. Cell. Neurosci. 10:269. doi: 10.3389/fncel.2016.00269 adverse environmental factors drive the onset and development of AD. Etiological drivers can be categorized as biotic stressors and abiotic stressors, with the latter category divided into physical stressors and chemical stressors. Ultimately, biotic/abiotic stressors can be integrated into reactive oxygen species (ROS)/oxidative stressors and reactive nitrogen species (RNS)/nitrosative stressors that impact the transition of neurons from dysfunction to death (Barone et al., 2011a,b; Butterfield et al., 2014).

Our opinion on biotic/abiotic stress-triggered $\mathrm{AD}$ links the various stressors to the genesis and progression of $\mathrm{AD}$ through a neuroinflammatory signaling cascade, which initiates nuclear factor $\kappa \mathrm{B}(\mathrm{NF}-\kappa \mathrm{B})$ and induces pro-inflammatory cytokines that evoke potent ROS/RNS burst for neuronal/glial killing. To trigger $\mathrm{AD}$, biotic stressors convey the external biological signals via lipopolysaccharide (LPS)-toll-like receptor 4 (TLR4), LPS-receptor of advanced glycation end products (RAGE), and amyloid $\beta$ peptide (A $\beta$ )/senile plaques (SP)-RAGE interactions (Yan et al., 1996; Yamamoto et al., 2011). Alternatively, abiotic stressors transduce the external non-biological signals via AGEs-RAGE, high-mobility group protein B1 (HMGB1)-RAGE, and A $\beta /$ SP-RAGE interactions (Mazarati et al., 2011; Horst et al., 2016). Specifically, hypothermia, as well as anesthesia and aging that induce hypothermia, can execute a neurotoxic role to kill neurons and glia via neurofibrillary tangles (NFTs) derived from hyperphosphorylated Tau (p-Tau) (Carrettiero et al., 2015; Figure 1).

Mounting evidence supports that LPS and interferon $\gamma$ (IFN- $\gamma$ ) activate microglia to induce a pro-inflammatory neurotoxic M1 phenotype, whereas interleukin 4 (IL-4), IL-10, IL-13, and transforming growth factor $\beta$ (TGF- $\beta$ ) activate microglia to give rise to an anti-inflammatory neuroprotective M2 phenotype (Tang and Le, 2016). Interestingly, we found that electric acupuncture can mimic mechanical wounding to firstly deteriorate LPS-induced AD-like brain pathogenesis, but secondly ameliorate the progressive neurodegeneration in a wounding-healing manner, suggesting a putative conversion from M1 microglia to M2 microglia (He, 2016). 


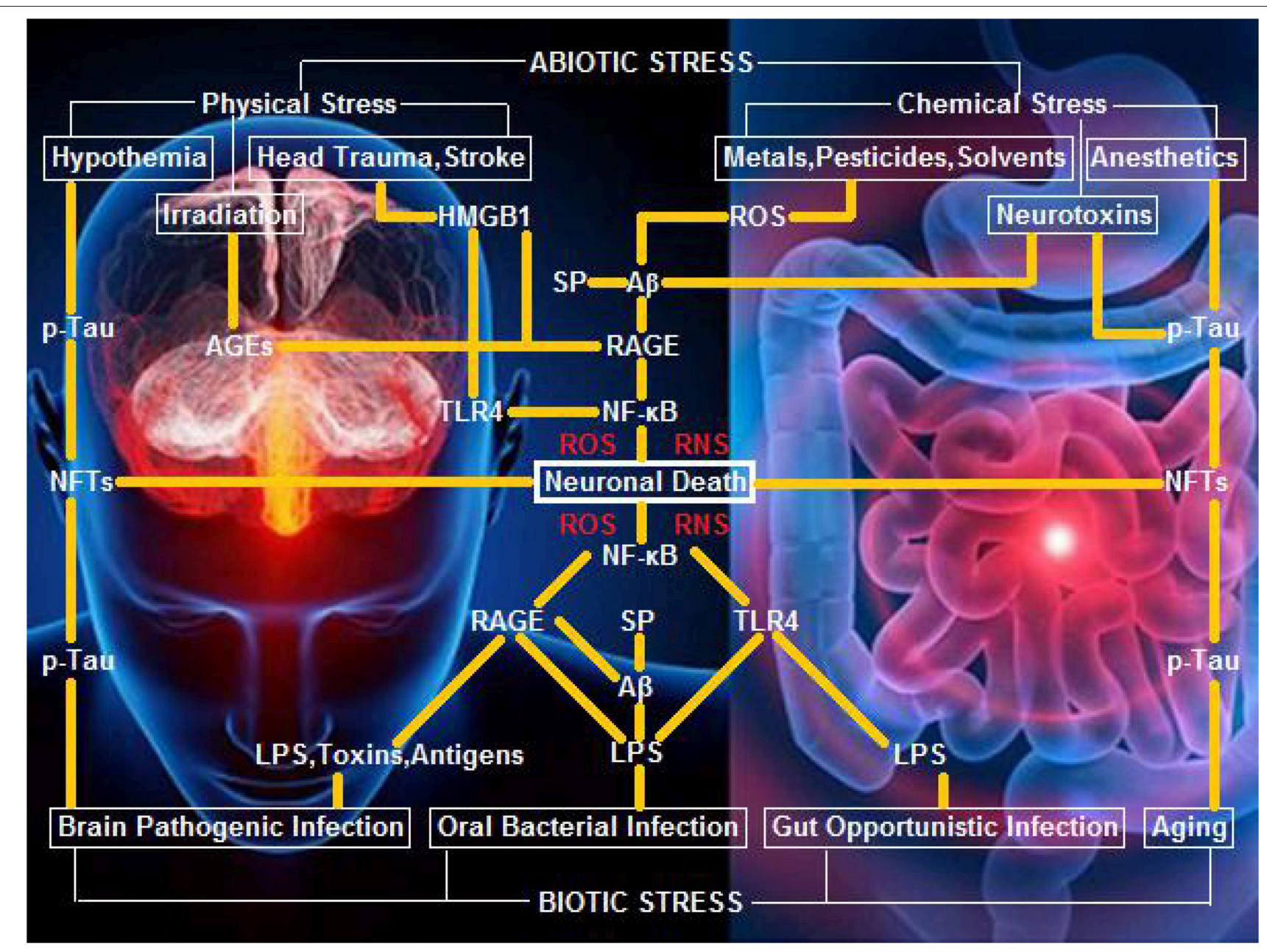

FIGURE 1 | A hypothetical schematic of biotic/abiotic stress-triggered AD. Biotic stress from brain, oral, or gut infection can activate NF- $\mathrm{KB}-\mathrm{primed}$ neuroinflammatory cascades, elicit ROS/RNS burst, and kill neurons and glia via LPS-TLR4/RAGE and A $\beta$ /SP-RAGE interactions and subsequent signaling. Abiotic stress encompassing physical stress (e.g., head trauma, stroke, or irradiation) and chemical stress (e.g., metals, pesticides, solvents, or neurotoxins) can also activate NF-кB-primed neuroinflammatory cascades, elicit ROS/RNS burst, and kill neurons and glia via AGEs-RAGE, HMGB1-RAGE/TLR4, and A $\beta$ /SP-RAGE interactions and downstream signaling. Hypothermia, anesthetics, and aging, can exert a neurotoxic effect upon exposure of neurons and glia to NFTs (the background figure was adopted from the website https://zhidao.baidu.com/daily/view?id=5979).

\section{BIOTIC STRESS AND AD}

Biotic stressors refer to any potential infectious pathogens or opportunistic infectious microbes, including Chlamydophila

Abbreviations: $\mathrm{A} \beta$, amyloid- $\beta$ peptide; $\mathrm{AD}$, Alzheimer's disease; AGEs, advanced glycation end products; AMP, antimicrobial peptide; APOE, apolipoprotein E gene; APP, amyloid precursor protein; $\mathrm{CH} 25 \mathrm{H}$, cholesterol 25-hydroxylase; Drp1, dynamin-related protein 1; HCMV, human cytomegalovirus; HMBG1, high-mobility group protein B1; HIV, human immunodeficiency virus; HSV-1, herpes simplex virus type 1; IDE, insulin-degrading enzyme; IFN, interferon; IL, interleukin; LPS, lipopolysaccharide; NFTs, neurofibrillary tangles; 25OHC, 25-hydroxycholesterol; NO, nitric oxide; RNS, reactive nitrogen species; ROS, reactive oxidative species; NF- $\kappa B$, nuclear factor $\kappa B$; RAGE, receptor of advanced glycation end products; SP, senile plaques; SRB, sulfate-reducing bacteria; SNP, single-nucleotide polymorphism; TGF, transforming growth factor; TLR4, toll-like receptor 4 . pneumoniae (Balin et al., 1998), Helicobacter pylori (Kountouras et al., 2012), Toxoplasma gondii (Prandota, 2014), human immunodeficiency virus (HIV; Borjabad and Volsky, 2012), and human cytomegalovirus (HCMV; Lurain et al., 2013). An international team recently urged that cerebral pathogenic infections by herpes simplex virus type 1 (HSV-1), C. pneumoniae, spirochetes, and fungi be considered as candidate AD initiators (Itzhaki et al., 2016). Similarly, extracerebral infectious pathogens were also considered as $\mathrm{AD}$ triggers; for example, oral pathogenic infections by the periodontal bacteria Porphyromonas gingivalis and Actinomyces naeslundii were identified as high-risk factors driving development toward AD (Noble et al., 2014; Singhrao et al., 2015). A recent study on gut microbiota dysbiosis indicated that intestinal microbiome alterations are related to the malfunctional motor phenotypes, suggesting the overgrowth of intestinal commensal microbes (i.e., 
opportunistic infection) acting as a neurodegenerative driver (Scheperjans et al., 2015).

Sulfate-reducing bacteria (SRB), such as the Gram-positive Firmicutes and Gram-negative Proteobacteria, colonize 50\% of human guts (Stewart et al., 2006). Among which Desulfovibrio piger was shown as the most common SRB in a surveyed cohort of healthy US adults (Scanlan et al., 2009). Chondroitin sulfate, a daily dietary nutrient available from livestock and poultry products, can increase the abundance of sulfatase-free $D$. piger upon reducing sulfate released from sulfatase-secreting Bacteroides thetaiotaomicron (Rey et al., 2013), thereby raising the possibility of $B$. thetaiotaomicron degrading mucin in the gut. Red meat containing heme can also nourish the mucindegrading bacteria (e.g., Akkermansia muciniphila; Ijssennagger et al., 2015). These observations predisposed that gut dysbiosis may lead to the thinned mucosal layers and permeable colon linings, which boost LPS leakage from the gut and entry into the blood stream (Qin et al., 2012).

Factors that link the leaky gut and serum LPS to neurodegenerative diseases include: the plasma level of LPS in patients with neurodegenerative disease is three times higher than in healthy persons (Zhang et al., 2009); and intraperitoneal injections of LPS into mice cause a prolonged elevation hippocampal $A \beta$ levels and lead to cognitive deficits (Kahn et al., 2012). To this end, intranasal LPS infusion was successfully used to establish a neurodegenerative model in rodents $(\mathrm{He}$ et al., 2013). According to a recent introduction by Scheperjans (2016) on the relevance of gut microbiota to $A \beta$ deposition, germ-free $\mathrm{APP}_{\mathrm{SWE}} / \mathrm{PS}_{\triangle \mathrm{E} 9}$ mice show mitigated amyloidosis in the brain compared with conventional $\mathrm{APP}_{\mathrm{SWE}} / \mathrm{PS}_{\triangle \mathrm{E} 9}$ mice. While colonization of germ-free $\mathrm{APP}_{\mathrm{SWE}} / \mathrm{PS}_{\triangle \mathrm{E}}$ mice with harvested gut microbiota from conventional $\mathrm{APP}_{\mathrm{SWE}} / \mathrm{PS} 1_{\triangle \mathrm{E}} 9$ mice aggravates cerebral amyloidosis, colonization with gut microbiota from wild-type mice fails to increase cerebral $A \beta$ levels.

Evidence supporting a possible infectious origin of $\mathrm{AD}$ is also derived from the sequencing-classified single nucleotide polymorphism (SNP) in apolipoprotein E gene (APOE), which is involved in modulating the immune response and infectious susceptibility (Verghese et al., 2011). Genome-wide association studies have revealed that several immune system components including virus receptor genes serve as risk factors for $\mathrm{AD}$ (Licastro et al., 2011). For example, cholesterol 25-hydroxylase $(\mathrm{CH} 25 \mathrm{H})$, catalyzing the generation of 25-hydroxycholesterol (25OHC) and inducing the enhancement of innate antiviral immunity, is selectively upregulated by virus infection (Blanc et al., 2013; Liu et al., 2013).

\section{ABIOTIC STRESS AND AD}

An epidemiological study has associated an increased risk of $\mathrm{AD}$ with a medical history of traumatic head injury (Webster et al., 2015). Moreover, brain inflammation seems a common consequence of mechanical insults such as trauma and stroke (Fiebich et al., 2014). Trauma can significantly increase expression of the alarmin HMBG1 (Horst et al., 2016), which in turn activates an inflammatory cascade by stimulating multiple receptors including RAGE and TLR4 (Mazarati et al., 2011). A recent study showed that $\mathrm{AD}$-like model mice, on a diet enriched in AGEs due to irradiation, exhibit significant memory dysfunction, accompanied with the hippocampal deposition of insoluble $A \beta 42$ fragment and AGEs (Lubitz et al., 2016). This latter finding was consistent with the notion that $\mathrm{A} \beta$ can activate microglia and induce neurotoxicity by RAGE binding (Yan et al., 1996).

Many naturally occurring and synthesized chemicals such as heavy metals, pesticides, bactericides, and solvents are ROS generators, and therefore are potential initiators of AD (ChinChan et al., 2015). A recent study showed that magnetite from air pollution might be an important risk factor for $\mathrm{AD}$; particularly, those magnetite pollutant particles that are $<200 \mathrm{~nm}$ in diameter can enter the brain directly via the olfactory bulb (Maher et al., 2016). Cyanobacteria or blue-green algae residing in the gut may produce the neurotoxin $\beta-\mathrm{N}$-methylamino-L-alanine (BMAA), which was implicated in the development of $\mathrm{AD}$ (Banack et al., 2010; Brenner, 2013). Chronic dietary exposure to BMAA was identified as a causal factor of neurodegeneration in the Chamorros villagers on the Pacific island of Guam, and vervets (Chlorocebus sabaeus) fed with BMAA-dosed fruit were observed to develop neurodegenerative diseases exhibiting $A \beta$ and NFTs (Cox et al., 2016).

It was highlighted that aggregation of p-Tau into NFTs or even development of tauopathies seems an essential consequence of hypothermia as well as anesthetic-induced hypothermia (Planel et al., 2007; Carrettiero et al., 2015). Due to reduced peripheral vasoconstriction, mitigated heat production, and other reasons, the core body temperature of healthy individuals over 60 years of age is $0.4^{\circ} \mathrm{C}$ lower than adults aged 20-60 years, suggesting that aging should facilitate $\mathrm{p}$-Tau formation by inducing cerebral hypothermia. It was suggested that tau phosphorylation at later stages is mostly a consequence of hypothermia although hyperphosphorylation at early stages may be due to the deregulation of JNK and PP2A (El-Khoury et al., 2016).

\section{EMERGING EVIDENCE OF A $\beta$ AS A RESPONDER TO INFECTION}

In contrast to the conventional assertion of a causative role of $\mathrm{A} \beta$ in $\mathrm{AD}$ pathogenesis, the peptide was surprisingly recognized as an antimicrobial peptide (AMP) with potent activity against pathogenic infections (Soscia et al., 2010). A $\beta$ has been confirmed to protect mouse, nematode, and cell culture models of $\mathrm{AD}$ from fungal and bacterial infections because propagating fibrils mediate the agglutination and eventual entrapment of pathogens. Indeed, bacterial infection by Salmonella typhimurium in the brains of transgenic $\mathrm{AD}$ mice results in accelerated $\mathrm{A} \beta$ deposition, which can co-localize with invading bacteria (Kumar et al., 2016). It was recently reported that a long-term antibiotic treatment regime inducing a prolonged change of gut microbiota decreases $A \beta$ deposition in the $\mathrm{APP}_{\mathrm{SWE}} / \mathrm{PS}_{\triangle \mathrm{E} 9}$ mouse $\mathrm{AD}$ model. In the observation, 
soluble $A \beta$ levels were elevated, plaque-localized glial reactivity attenuated, and microglial morphology altered, suggesting a diversity of gut microbiota regulating host innate immunity, and impacting amyloidosis (Minter et al., 2016).

$\mathrm{A} \beta$ was also found to possess antiviral activity against HSV-1 and influenza A (White et al., 2014; Bourgade et al., 2015, 2016). Interestingly, another AMP, $\beta$-defensin 1 , has similarly shown overproduction in AD patients (Williams et al., 2013). An SNP in human $\mathrm{CH} 25 \mathrm{H}$ governs both $\mathrm{AD}$ susceptibility and $\mathrm{A} \beta$ deposition, implying $A \beta$ induction may be a 25OHC target, and also providing a potential mechanistic link between pathogenic infection and $\mathrm{A} \beta$ accumulation (Papassotiropoulos et al., 2005; Lathe et al., 2014).

\section{A $\beta$ AS A TARGET FOR A POTENTIAL AD REMEDY}

Why $A \beta$ progressively deposits remains largely unknown, but $S$-nitrosylation of cysteine residues in $A \beta$-degrading enzymes might be relevant, and nitric oxide (NO) involved. The impact from NO-mediated nitrosative stress was found to prompt the S-nitrosylation of insulin-degrading enzyme (IDE) and dynamin-related protein 1 (Drp1) responsible for $A \beta$ degradation, thus inhibiting $A \beta$ catabolism and hyperactivating mitochondrial fission machinery. The raised $A \beta$ levels and compromised mitochondrial bioenergetics were shown to result in dysfunctional synaptic plasticity and synapse loss in cortical and hippocampal neurons (Akhtar et al., 2016).

Interventions against $\mathrm{AD}$ involving eradicating $\mathrm{A} \beta$ from brain tissues hold promise in avoiding microglial activation, immune attack, and neuron killing. It was shown that aducanumab, a human monoclonal antibody that selectively targets the aggregated $A \beta$, enters the brain, binds parenchymal $A \beta$, and reduces $\mathrm{A} \beta$ in a transgenic mouse $\mathrm{AD}$ model, and that aducanumab even reduces brain $A \beta$ in patients with prodromal $\mathrm{AD}$ after 1 year of monthly intravenous infusions (Sevigny et al., 2016).

Alternatively, prohibition of $A \beta$ formation by impeding the cleavage of APP might also prevent AD. An ongoing

\section{REFERENCES}

Akhtar, M. W., Sanz Blasco, S., Donatabadi, N., Parker, J., Chon, K., Lee, M. S., et al. (2016). Elevated glucose and oligomeric $\beta$-amyloid disrupt synapses via a common pathway of aberrant protein S-nitrosylation. Nat. Commun. 7:10242. doi: $10.1038 /$ ncomms 10242

Balin, B. J., Gerard, H. C., Arking, E. J., Appelt, D. M., Branigan, P. J., Abrams, J. T., et al. (1998). Identification and localization of Chlamydia pneumoniae in the Alzheimer's brain. Med. Microbiol. Immunol. 187, 23-42.

Ballard, C., Gauthier, S., Corbett, A., Brayne, C., Aarsland, D., and Jones, E. (2011). Alzheimer's disease. Lancet 377, 1019-1031. doi: 10.1016/S01406736(10)61349-9

Banack, S. A., Caller, T. A., and Stommel, E. W. (2010). The cynobacteria derived toxin beta-N-methylamino-L-alanine and amyotrophic lateral sclerosis. Toxins (Basel) 2, 2837-2850. doi: 10.3390/toxins2122837

Barone, E., Cenini, G., Di Domenico, F., Martin, S., Sultana, R., Mancuso, C., et al. (2011a). Long-term high-dose atorvastatin decreases brain oxidative human trial is assessing the therapeutic value of the $\beta$-secretase inhibitor solanezumab (Sheridan, 2015) although a clinical trial with the $\gamma$-secretase inhibitor semagacestat failed just 1 year ago (De Strooper, 2014). The preliminary data indicated that solanezumab can decrease cognitive decline in mild $\mathrm{AD}$ by about $30 \%$ in a clinical study recruiting 440 subjects (Reardon, 2015).

\section{PROSPECTIVES}

Considering $\mathrm{A} \beta$ as a pathogenic hallmark of $\mathrm{AD}$, it is anticipated that treatments by monoclonal antibodies to remove $A \beta$ or block APP cleavage would justify optimism and show progress in clinical trials. However, $A \beta$ is unlikely an initiator, and more likely a mediator of $\mathrm{AD}$, so $\mathrm{A} \beta$-targeted interventions should not be an eventual solution to attenuating progressive aggravation toward AD. Once infectious agents have been verified as the primordial etiological cues leading to $\mathrm{AD}$, the more practical medications treating $\mathrm{AD}$ should at least include, for example, anti-infection agents such as minocycline (ElShimy et al., 2015; Budni et al., 2016), anti-inflammation agents such as anhydroexfoliamycin (Leirós et al., 2015) or rapamycin (Siman et al., 2015), and anti-oxidation agents such as allicin (Zhu et al., 2015). With similar importance, modulation of gut microbiota from dysbiosis to homeostasis for the early-phase prophylaxis of AD through personalized diet and prebiotic/probiotic supplementation should also be addressed (Hu et al., 2016).

\section{AUTHOR CONTRIBUTIONS}

QPZ wrote the manuscript. CQL, QZ, and QW critically reviewed the manuscript. All authors read and approved the final version of the manuscript.

\section{ACKNOWLEDGMENTS}

We thank Shi-Jie Zhang, Jiang He, Tao Liao, and Yan-Ping Chen for their assistance in manuscript preparation. This work was supported by the National Natural Science Foundation of China (NSFC, No. 81273620 to QPZ and No. 81673861 to CQL). and nitrosative stress in a preclinical model of Alzheimer disease: a novel mechanism of action. Pharmacol. Res. 63, 172-180. doi: 10.1016/j.phrs.2010. 12.007

Barone, E., Di Domenico, F., Cenini, G., Sultana, R., Coccia, R., Preziosi, P., et al. (2011b). Oxidative and nitrosative modifications of biliverdin reductase- $\mathrm{A}$ in the brain of subjects with Alzheimer's disease and amnestic mild cognitive impairment. J. Alzheimers Dis. 25, 623-633. doi: 10.3233/JAD-2011-110092

Blanc, M., Hsieh, W. Y., Robertson, K. A., Kropp, K. A., Forster, T., Shui, G., et al. (2013). The transcription factor STAT-1 couples macrophage synthesis of 25hydroxycholesterol to the interferon antiviral response. Immunity 38, 106-118. doi: 10.1016/j.immuni.2012.11.004

Borjabad, A., and Volsky, D. J. (2012). Common transcriptional signatures in brain tissue from patients with HIV-associated neurocognitive disorders, Alzheimer's disease, and multiple sclerosis. J. Neuroimmune Pharmacol. 7, 914-726. doi: 10. 1007/s11481-012-9409-5

Bourgade, K., Garneau, H., Giroux, G., Le Page, Y., Bocti, C., Dupuis, G., et al. (2015). $\beta$-amyloid peptides display protective activity against the human 
Alzheimer's disease-associated herpes simplex virus-1. Biogerontology 16, 85-98. doi: 10.1007/s10522-014-9538-8

Bourgade, K., Le Page, A., Bocti, C., Witkowski, J. M., Dupuis, G., Frost, E. H., et al. (2016). Protective effect of amyloid-beta peptides against herpes simplex virus1 infection in a neuronal cell culture model. J. Alzheimers. Dis. 50, 1227-1241. doi: 10.3233/JAD-150652

Brenner, S. R. (2013). Blue-green algae or Cyanobacteria in the intestinal micro-flora may produce neurotoxins such as beta- $\mathrm{N}$-methylamino-L-alanine (BMAA) which may be related to development of amyotrophic lateral sclerosis, Alzheimer's disease, and Parkinson-dementia-complex in humans and equine motor neuron disease in horses. Med. Hypotheses 80, 103. doi: 10.1016/j.mehy. 2012.10.010

Budni, J., Garcez, M. L., de Medeiros, J., Cassaro, E., Santos-Bellettini, T., Mina, F., et al. (2016). The anti-inflammatory role of minocycline in Alzheimer's disease. Curr. Alzheimer Res. 13, 1319-1329. doi: 10.2174/ 1567205013666160819124206

Butterfield, D. A., Di Domenico, F., and Barone, E. (2014). Elevated risk of type 2 diabetes for development of Alzheimer disease: a key role for oxidative stress in brain. Biochim. Biophys. Acta 1842, 1693-1706. doi: 10.1016/j.bbadis.2014. 06.010

Carrettiero, D. C., Santiago, F. E., Motzko-Soares, A. C., and Almeida, M. C. (2015). Temperature and toxic Tau in Alzheimer's disease: new insights. Temperature (Austin) 2, 491-498. doi: 10.1080/23328940.2015.1096438

Chin-Chan, M., Navarro-Yepes, J., and Quintanilla-Vega, B. (2015). Environmental pollutants as risk factors for neurodegenerative disorders: Alzheimer and Parkinson diseases. Front. Cell. Neurosci. 9:124. doi: 10.3389/ fncel.2015.00124

Cox, P. A., Davis, D. A., Mash, D. C., Metcalf, J. S., and Banack, S. A. (2016). Dietary exposure to an environmental toxin triggers neurofibrillary tangles and amyloid deposits in the brain. Proc. Biol. Sci. 283:20152397. doi: 10.1098/rspb.2015.2397

De Strooper, B. (2014). Lessons from a failed $\gamma$-secretase Alzheimer trial. Cell 159, 721-726. doi: 10.1016/j.cell.2014.10.016

El-Khoury, N. B., Gratuze, M., Petry, F., Papon, M. A., Julien, C., Marcouiller, F., et al. (2016). Hypothermia mediates age-dependent increase of tau phosphorylation in db/db mice. Neurobiol. Dis. 88, 55-65. doi: 10.1016/j.nbd. 2016.01.005

El-Shimy, I. A., Heikal, O. A., and Hamdi, N. (2015). Minocycline attenuates A $\beta$ oligomers-induced pro-inflammatory phenotype in primary microglia while enhancing A $\beta$ fibrils phagocytosis. Neurosci. Lett. 609, 36-41. doi: 10.1016/j. neulet.2015.10.024

Fiebich, B. L., Akter, S., and Akundi, R. S. (2014). The two-hit hypothesis for neuroinflammation: role of exogenous ATP in modulating inflammation in the brain. Front. Cell. Neurosci. 8:260. doi: 10.3389/fncel.2014.00260

Hardy, J., and Allsop, D. (1991). Amyloid deposition as the central event in the aetiology of Alzheimer's disease. Trends Pharmacol. Sci. 12, 383-388. doi: 10. 1016/0165-6147(91)90609-V

He, J. (2016). Electroacupuncture Ameliorates Collagen-Induced Alzheimer's Disease-like Brain Pathogenesis in Mice. Dissertation/master's thesis, Guangzhou University of Chinese Medicine, China.

He, Q., Yu, W., Wu, J., Chen, C., Lou, Z., Zhang, Q., et al. (2013). Intranasal LPSmediated Parkinson's model challenges the pathogenesis of nasal cavity and environmental toxins. PLoS ONE 8:e78418. doi: 10.1371/journal.pone.0078418

Horst, K., Eschbach, D., Pfeifer, R., Relja, B., Sassen, M., Steinfeldt, T., et al. (2016). Long-term effects of induced hypothermia on local and systemic inflammation - Results from a porcine long-term trauma model. PLOS ONE 11:e0154788. doi: 10.1371/journal.pone.0154788

Hu, X., Wang, T., and Jin, F. (2016). Alzheimer's disease and gut microbiota. Sci. China Life Sci. 59, 1006-1023. doi: 10.1007/s11427-016-5083-9

Ijssennagger, N., Belzer, C., Hooiveld, G. J., Dekker, J., van Mil, S. W., Müller, M., et al. (2015). Gut microbiota facilitates dietary hemeinduced epithelial hyperproliferation by opening the mucus barrier in colon. Proc. Natl. Acad. Sci. U.S.A. 112, 10038-10043. doi: 10.1073/pnas. 1507645112

Itzhaki, R. F., Lathe, R., Balin, B. J., Ball, M. J., Bearer, E. L., Braak, H., et al. (2016). Microbes and Alzheimer's disease. J. Alzheimers Dis. 51, 979-984. doi: 10.3233/ JAD-160152

Kahn, M. S., Kranjac, D., Alonzo, C. A., Haase, J. F., Cedillos, R. O., McLinden, K. A., et al. (2012). Prolonged elevation in hippocampal A beta and cognitive deficits following repeated endotoxin exposure in the mouse. Behav. Brain Res. 229, 176-184. doi: 10.1016/j.bbr.2012.01.010

Kountouras, J., Bozik, M., Zavos, C., Gavalas, E., Giartza-Taxidou, E., Venizelos, I., et al. (2012). A potential impact of chronic Helicobacter pylori infection on Alzheimer's disease pathobiology and course. Neurobiol. Aging 33, e3-e4. doi: 10.1016/j.neurobiolaging.2012.01.003

Kumar, D. K., Choi, S. H., Washicosky, K. J., Eimer, W. A., Tucker, S., et al. (2016). Amyloid- $\beta$ peptide protects against microbial infection in mouse and worm models of Alzheimer's disease. Sci. Transl. Med. 8, 340ra72. doi: 10.1126/ scitranslmed.aaf1059

Lathe, R., Sapronova, S., and Kotelevtsev, Y. (2014). Atherosclerosis and Alzheimer-diseases with a common cause? Inflammation, oxysterols, vasculature. BMC Geriatr. 14:36. doi: 10.1186/1471-2318-14-36

Leirós, M., Alonso, E., Rateb, M. E., Ebel, R., Jaspars, M., Alfonso, A., et al. (2015). The streptomyces metabolite anhydroexfoliamycin ameliorates hallmarks of Alzheimer's disease in vitro and in vivo. Neuroscience 305, 26-35. doi: 10.1016/ j.neuroscience.2015.07.082

Licastro, F., Carbone, I., Ianni, M., and Porcellini, E. (2011). Gene signature in Alzheimer's disease and environmental factors: the virus chronicle. $J$. Alzheimers Dis. 27, 809-817. doi: 10.3233/JAD-2011-110755

Liu, S. Y., Aliyari, R., Chikere, K., Li, G., Marsden, M. D., Smith, J. K., et al. (2013). Interferon-inducible cholesterol-25-hydroxylase broadly inhibits viral entry by production of 25-hydroxycholesterol. Immunity 38, 92-105. doi: 10. 1016/j.immuni.2012.11.005

Lubitz, I., Ricny, J., Atrakchi-Baranes, D., Shemesh, C., and Kravitz, E. (2016). High dietary advanced glycation end products are associated with poorer spatial learning and accelerated $\mathrm{A} \beta$ deposition in an Alzheimer mouse model. Aging Cell 15, 309-316. doi: 10.1111/acel.12436

Lurain, N. S., Hanson, B. A., Martinson, J., Leurgans, S. E., Landay, A. L., Bennett, D. A., et al. (2013). Virological and immunological characteristics of human cytomegalovirus infection associated with Alzheimer disease. J. Infect. Dis. 208, 564-572. doi: 10.1093/infdis/jit210

Maher, B. A., Ahmed, I. A. M., Karloukovski, V., MacLaren, D. A., Foulds, P. G., Allsop, D., et al. (2016). Magnetite pollution nanoparticles in the human brain. Proc. Natl. Acad. Sci. U.S.A. 113, 10797-10801. doi: 10.1073/pnas.16059 41113

Mazarati, A., Maroso, M., Iori, V., Vezzani, A., and Carli, M. (2011). High-mobility group box-1 impairs memory in mice through both toll-like receptor 4 and Receptor for Advanced Glycation End Products. Exp. Neurol. 232, 143-148. doi: 10.1016/j.expneurol.2011.08.012

Minter, M. R., Zhang, C., Leone, V., Ringus, D., Zhang, X., Oyler-Castrillo, P., et al. (2016). Antibiotic-induced perturbations in gut microbial diversity influences neuro-inflammation and amyloidosis in a murine model of Alzheimer's disease. Sci. Rep. 6:30028. doi: 10.1038/srep30028

Mudher, A., and Lovestone, S. (2002). Alzheimer's disease-do tauists and baptists finally shake hands? Trends Neurosci. 25, 22-26. doi: 10.1016/S01662236(00)02031-2

Noble, J. M., Scarmeas, N., Celenti, R. S., Elkind, M. S. V., Wright, C. B., Schupf, N., et al. (2014). Serum IgG antibody levels to periodontal microbiota are associated with incident Alzheimer's disease. PLOS ONE 9:e114959. doi: 10. 1371/journal.pone.0114959

Papassotiropoulos, A., Lambert, J. C., Wavrant-De Vrieze, F., Wollmer, M. A., von der Kammer, H., and Streffer, J. R. (2005). Cholesterol 25hydroxylase on chromosome $10 \mathrm{q}$ is a susceptibility gene for sporadic Alzheimer's disease. Neurodegener. Dis. 2, 233-241. doi: 10.1159/ 000090362

Planel, E., Richter, K. E., Nolan, C. E., Finley, J. E., Liu, L., Wen, Y., et al. (2007). Anesthesia leads to tau hyperphosphorylation through inhibition of phosphatase activity by hypothermia. J. Neurosci. 27, 3090-3097. doi: 10.1523/ JNEUROSCI.4854-06.2007

Prandota, J. (2014). Possible link between Toxoplasma gondii and the anosmia associated with neurodegenerative diseases. Am. J. Alzheimers Dis. Other Demen. 29, 205-214. doi: 10.1177/1533317513517049

Qin, J., Li, Y., Cai, Z., Li, S., Zhu, J., Zhang, F., et al. (2012). A metagenomewide association study of gut microbiota in type 2 diabetes. Nature 490, 55-60. doi: $10.1038 /$ nature 11450

Reardon, S. (2015). Antibody drugs for Alzheimer's show glimmers of promise. Nature 523, 509-510. doi: 10.1038/nature.2015.18031 
Rey, F. E., Gonzalez, M. D., Cheng, J., Wu, M., Ahern, P. P., and Gordon, J. I. (2013). Metabolic niche of a prominent sulfate-reducing human gut bacterium. Proc. Natl. Acad. Sci. U.S.A. 110, 13582-13587. doi: 10.1073/pnas.1312524110

Scanlan, P. D., Shanahan, F., and Marchesi, J. R. (2009). Culture-independent analysis of desulfovibrios in the human distal colon of healthy, colorectal cancer and polypectomized individuals. FEMS Microbiol. Ecol. 69, 213-221. doi: 10. 1111/j.1574-6941.2009.00709.x

Scheperjans, F. (2016). Can microbiota research change our understanding of neurodegenerative diseases? Neurodegener. Dis. Manage. 6, 81-85. doi: 10.2217/ nmt-2015-0012

Scheperjans, F., Aho, V., Pereira, P. A., Koskinen, K., Paulin, L., Pekkonen, E., et al. (2015). Gut microbiota are related to Parkinson's disease and clinical phenotype. Mov. Disord. 30, 350-358. doi: 10.1002/mds.26069

Sevigny, J., Chiao, P., Bussiere, T., Weinreb, P. H., Williams, L., Maier, M., et al. (2016). The antibody aducanumab reduces $A \beta$ plaques in Alzheimer's disease. Nature 537, 50-56. doi: 10.1038/nature 19323

Sheridan, C. (2015). Pivotal trials for $\beta$-secretase inhibitors in Alzheimer's. Nat. Biotechnol. 33, 115-116. doi: 10.1038/nbt0215-115

Siman, R., Cocca, R., and Dong, Y. (2015). The mTOR inhibitor rapamycin mitigates perforant pathway neurodegeneration and synapse loss in a mouse model of early-stage Alzheimer-type tauopathy. PLOS ONE 10:e142340. doi: 10.1371/journal.pone.0142340

Singhrao, S. K., Harding, A., Poole, S., Kesavalu, L., and Crean, S. (2015). Porphyromonas gingivalis periodontal infection and its putative links with Alzheimer's disease. Mediat. Inflamm. 2015:137357. doi: 10.1155/2015/ 137357

Soscia, S. J., Kirby, J. E., Washicosky, K. J., Tucker, S. M., Ingelsson, M., Hyman, B., et al. (2010). The Alzheimer's disease-associated amyloid beta-protein is an antimicrobial peptide. PLoS ONE 5:e9505. doi: 10.1371/journal.pone.0009505

Stewart, J. A., Chadwick, V. S., and Murray, A. (2006). Carriage, quantification, and predominance of methanogens and sulfate-reducing bacteria in faecal samples. Lett. Appl. Microbiol. 43, 58-63. doi: 10.1111/j.1472-765X.2006.01906.x

Tang, Y., and Le, W. (2016). Differential roles of M1 and M2 microglia in neurodegenerative diseases. Mol. Neurobiol. 53, 1181-1194. doi: 10.1007/ s12035-014-9070-5

Verghese, P. B., Castellano, J. M., and Holtzman, D. M. (2011). Apolipoprotein $\mathrm{E}$ in Alzheimer's disease and other neurological disorders. Lancet Neurol. 10, 241-252. doi: 10.1016/S1474-4422(10)70325-2
Webster, S. J., Van Eldik, L. J., Watterson, D. M., and Bachstetter, A. D. (2015) Closed head injury in an age-related Alzheimer mouse model leads to an altered neuroinflammatory response and persistent cognitive impairment. J. Neurosci. 35, 6554-6569. doi: 10.1523/JNEUROSCI.0291-15.2015

White, M. R., Kandel, R., Tripathi, S., Condon, D., Qi, L., Taubenberger, J., et al. (2014). Alzheimer's associated beta-amyloid protein inhibits influenza A virus and modulates viral interactions with phagocytes. PLoS ONE 9:e101364. doi: 10. 1371/journal.pone.0101364

Williams, W. M., Torres, S., Siedlak, S. L., Castellani, R. J., Perry, G., Smith, M. A et al. (2013). Antimicrobial peptide beta-defensin-1 expression is upregulated in Alzheimer's brain. J. Neuroinflammation 10:127. doi: 10.1186/1742-209410-127

Yamamoto, Y., Harashima, A., Saito, H., Tsuneyama, K., Munesue, S., Motoyoshi, S., et al. (2011). Septic shock is associated with receptor for advanced glycation end products ligation of LPS. J. Immunol. 186, 3248-3257. doi: 10.4049/ jimmunol.1002253

Yan, S. D., Chen, X., Fu, J., Chen, M., Zhu, H., Roher, A., et al. (1996). RAGE and amyloid-beta peptide neurotoxicity in Alzheimer's disease. Nature 382 685-691.

Zhang, R., Miller, R. G., Gascon, R., Champion, S., Katz, J., Lancero, M., et al. (2009). Circulating endotoxin and systemic immune activation in sporadic amyotrophic lateral sclerosis (sALS). J. Neuroimmunol. 206, 121-124. doi: 10. 1016/j.jneuroim.2008.09.017 $\beta$

Zhu, Y. F., Li, X. H., Yuan, Z. P., Li, C. Y., Tian, R. B., and Jia, W. (2015). Allicin improves endoplasmic reticulum stress-related cognitive deficits via PERK/Nrf2 antioxidative signaling pathway. Eur. J. Pharmacol. 762, 239-246. doi: 10.1016/j.ejphar.2015.06.002

Conflict of Interest Statement: The authors declare that the research was conducted in the absence of any commercial or financial relationships that could be construed as a potential conflict of interest.

Copyright (c) 2016 Li, Zheng, Wang and Zeng. This is an open-access article distributed under the terms of the Creative Commons Attribution License (CC BY). The use, distribution or reproduction in other forums is permitted, provided the original author(s) or licensor are credited and that the original publication in this journal is cited, in accordance with accepted academic practice. No use, distribution or reproduction is permitted which does not comply with these terms. 